\title{
El mundo iba en una dirección y el virus aumentó la prisa
}

Guillermo Borella*

Entre los diversos retos a los que debió enfrentarse la humanidad a lo largo del tiempo, las enfermedades han sido siempre un enemigo particularmente cruel y poderoso. No es exagerado decir que la historia fue moldeada por el impacto de las epidemias. Basta recordar cómo los pueblos originarios fueron diezmados por enfermedades importadas de Europa, donde la lucha contra numerosas plagas mortales acompañó la formación de los Estados modernos, forzándolos a recurrir a la higiene pública y las cuarentenas.

Hoy el coronavirus está causando cientos de miles de muertes, además de haber paralizado la economía mundial y alterado por completo la vida de la mayoría de las personas. Sin embargo, de cara al futuro, uno de los legados más importantes del COVID-19 será la forma en que la llegada de esta pandemia se articula con una serie de cambios preexistentes, propios de un mundo en transición.

Multilateralismo degradado y nacionalismos reforzados, crisis de gobernanza global, malestar con la democracia liberal y des-globalización. Si bien estas tendencias venían ya manifestándose desde hace algún tiempo, el caos desatado con la llegada de la pandemia no ha hecho más que profundizarlas, dejándolas así en evidencia. La epidemia es un factor más que se añade, pero los dilemas son los mismos y la situación económica los agrava. El mundo iba en una dirección y el virus aumentó la prisa.

La incapacidad de los principales líderes mundiales para concertar una salida colectiva a la crisis desatada por el COVID-19, ofreciendo una solución global a un problema de naturaleza también global, terminó por confirmar los pronósticos que vienen anunciando el fin del orden internacional liberal. Los líderes mundiales parecen haber olvidado la lección de que cualquier problema global requiere una solución global.

Según la mirada de Dani Rodrik, profesor de Economía Política en la Universidad de Harvard, la crisis global que estamos atravesando parece haber puesto aún más de relieve las características dominantes de la política de cada país. En efecto los países se han convertido en "versiones exageradas de sí mismos", dice Rodrik. Esto sugiere que la crisis tal vez no sea el punto de inflexión en la política y en la economía global que muchos auguraban. "En lugar de colocar al mundo en una trayectoria significativamente diferente, es probable que intensifique y afiance las tendencias ya existentes", advierte el académico en un artículo publicado en abril en Project Syndicate (Rodrik,2020).

\footnotetext{
* Magister en Periodismo, Universidad Torcuato Di Tella (LN/UTDT, Argentina); Licenciado en Relaciones Internacionales, Universidad Nacional de Rosario (UNR, Argentina); Profesor visitante del Departamento de Estudios Históricos y Sociales, UTDT (2017-2019); Profesor titular de "Introducción al Periodismo" y "Periodismo Internacional"; Periodista colaborador del diario La Nación desde 2016. Correo electrónico: guillermoborella@gmail.com
} 
Algo similar plantea Juan Gabriel Tokatlian, para quien, al menos en el corto plazo, la pospandemia no derivará en un replanteamiento sustantivo y progresista de las relaciones internacionales. Más aún, -dice Tokatlian- es probable que se exacerben tensiones y contradicciones vigentes y que ingresemos a un escenario muy delicado, no ya volátil en lo económico e inestable en lo político, sino profundamente turbulento y potencialmente descontrolado en múltiples niveles y ámbitos.

Entre las principales causas de la rápida propagación del coronavirus a escala planetaria podemos señalar la ausencia total de la coordinación internacional y la falta de memoria histórica en relación a las lecciones sobre las mejores prácticas a la hora de enfrentar una pandemia que nos dejaron los casos recientes como la influenza del SARS en 2003 y el H1N1 en 2009.

La situación límite, asimismo, ha acelerado las tendencias hacia la crisis de la globalización y del multilateralismo. En un mundo interdependiente, las acciones unilaterales tienden a ser ineficientes y contraproducentes. Sin embargo, la respuesta tardía o dilatada de los Estados ha profundizado enfoques de seguridad nacional como el cierre de fronteras, la prohibición de reuniones sociales, la movilización de los ejércitos, el bloqueo sanitario y los toques de queda.

Estas medidas han estado a la orden del día ante la rápida expansión de la epidemia, imponiéndose sobre las soluciones que apuestan a la cooperación y la solidaridad global. A pesar del rol clave que está jugando la Organización Mundial de la Salud (OMS) en la crisis en curso -algo con lo que Donald Trump no parece estar muy de acuerdo, dada su decisión de congelar los fondos que aporta su país a la organización-, queda claro que la autoridad de estos organismos debe verse reforzada. Especialmente, si tenemos en cuenta que sucesos similares pueden repetirse en el futuro.

Es importante subrayar que el riesgo de una pandemia figura hace años entre los riesgos globales identificados en el Informe Global de Riesgos, elaborado anualmente por el Foro Económico Mundial ${ }^{1}$. Este es apenas un ejemplo. Hay otros.

"Nos enfrentamos a la amenaza muy real de una pandemia fulminante, sumamente mortífera, provocada por un patógeno respiratorio que podría matar de 50 a 80 millones de personas y liquidar casi el 5\% de la economía mundial. Una pandemia mundial de esa escala sería una catástrofe y desencadenaría caos, inestabilidad e inseguridad generalizadas".

El mensaje no pudo haber sido más claro. Este vaticinio fue publicado en septiembre de 2019, tres meses antes de que se registre el primer paciente de COVID-19 en Wuhan. ¿Quién lo publicó? Nada más y nada menos que la Junta de Vigilancia Mundial de la Preparación ante Crisis Sanitarias, un órgano creado en 2018 por encargo de la OMS y el Banco Mundial con el objetivo de "prepararse ante las emergencias sanitarias de ámbito mundial y mitigar sus efectos", a partir de la experiencia de la epidemia de ébola que azotó varios países africanos entre 2014 y 2016. El informe, titulado Un Mundo en Peligro fue terminante: "El mundo no está preparado" 2 .

Casi diez años atrás, durante la crisis financiera internacional de 2008, el G20 se mostraba proactivo y comprometido, ofreciendo una respuesta efectiva y coordinada a la crisis financiera. La ayuda propuesta por el G20 en ese entonces cuadriplicó los recursos del Fondo Monetario Internacional (FMI) y una buena parte se usó para facilitar fondos de emergencias

\footnotetext{
${ }^{1}$ El Informe completo está disponible en http://www3.weforum.org/docs/WEF_Global_Risk_Report_2020.pdf

$\begin{array}{lcccc}\frac{\text { El }}{2} & \text { Informe } & \text { completo } & \text { está } & \text { disponible } \\ \text { https://apps.who.int/gpmb/assets/annual_report/GPMB } & \text { Annual_Report_Spanish.pdf }\end{array}$
}


para los países que lo necesitaran. Hoy, al menos de momento, no hay nada de eso. Esta vez, en cambio, el G20 se reunió tarde y sólo testimonialmente, sin alcanzar ninguna medida concreta.

En contraste, estamos ante un mundo que observa con pavor cómo ciertos líderes reaccionan negando el peligro y burlándose de una amenaza invisible, pero con consecuencias a la vista: los contagiados se cuentan de a millones y cientos de miles murieron a causa del virus desde su aparición en la ciudad china de Wuhan, a fines de 2019. Eso sin contar el descalabro económico resultante de esta catástrofe que sin dudas marcará un antes y un después en la historia de la humanidad.

En un escenario tan adverso donde todo parece estar en juego, surgen algunos interrogantes sobre las consecuencias de esta crisis multidimensional para el tablero geopolítico mundial y las lecciones que deja para el multilateralismo y el futuro de la globalización.

Estamos ante una crisis que registra una doble dimensión: una crisis sanitaria -más inmediata- y una crisis económica -que recién empieza-. Se trata, además, de una crisis propia de la globalización, particularmente si tenemos en cuenta la velocidad con que se propagó desde China hacia el resto del mundo.

Un elemento adicional que constituye el telón de fondo sobre el que se despliega esta crisis multidimensional provocada por la pandemia es el malestar con la democracia liberal. La sensación de que la democracia sirve a los intereses de unos pocos y de que está desconectada de las necesidades reales de la gente podría acrecentarse ante las dificultades actuales provocadas por el virus, sacando a relucir un sistema sobrecargado de tensiones y contradicciones, desnudando así las deficiencias de los postergados sistemas de salud pública.

Aquí también, la crisis financiera de 2008 -junto con la crisis sanitaria provocada un año después por la gripe porcina- sirven de perfecta analogía. En aquel momento, las sociedades esperaban que de allí emergiera una mayor regulación estatal sobre el capital financiero, a la vez que se reforzaran los sistemas de salud. Sin embargo, ¿cuánto cambió el mundo desde entonces? Nada de esto ocurrió. Por el contrario, hoy el capital financiero sigue desregulado, y las deficiencias de los sistemas sanitarios en el mundo están a la vista. En adelante, habrá que ver si podemos esperar una nueva forma de articular la relación entre Estado, sociedad y mercado.

Otra de las manifestaciones de esta globalización en jaque es la erosión de las instancias multilaterales. Al menos a corto plazo, la crisis provocada por la pandemia ha demostrado que el multilateralismo no atraviesa su mejor momento. Mientras tanto, estamos ante una peligrosa dinámica del "sálvese quien pueda", sin soluciones multilaterales a la vista: ni están ni se las espera. La cooperación internacional debería ser un imperativo. Esta es una crisis global y solamente vamos a salir juntos de ella.

Las consecuencias sobre el proceso globalizador amenazan con alterar las cadenas de suministro global, provocando una reubicación de la producción. Todo indica que estas cadenas se van a acortar y las economías volverán a lo nacional, priorizando la estabilidad sobre la eficiencia. Se avecina un posible reemplazo del modelo just in time por el de inventarios. El recuerdo del virus dejará su huella, habiendo reflejado la fragilidad del sistema de producción ante las interrupciones súbitas.

De un lado, algunos dicen que vamos hacia una des-globalización, es decir, una división global del trabajo desintegrada en bloques económicos competidores. Del otro, opinan que la globalización seguirá, solo que estará más centrada en China. En lo que todos parecen estar de acuerdo, en todo caso, es que se avecinan tiempos de cambio. Fuera lo que fuese, esto no es algo que haya provocado el coronavirus. En todo caso, esta pandemia va a acelerar aún más ese cambio y se profundizarán aquellas tendencias que ya se venían manifestando en el mundo, como el proteccionismo comercial. 
Las graves consecuencias que traerá el desplome súbito de la actividad económica global está siendo terrorífico. El FMI prevé una caída de la economía global del 3\% en 2020, la mayor contracción desde 1930. Para limitar el impacto de una crisis que apunta a ser "mucho mayor" que la de 2009 (según el último informe del FMI) (Guimón, 2020) hace falta una coordinación macroeconómica global que brilla por su ausencia.

Esto es grave en todos los casos, pero lo es particularmente en los países en desarrollo con economías muy endeudadas, donde el capital está saliendo a raudales y no tienen en qué apoyarse. Al final del día, los países de la Unión Europea pueden recurrir a las líneas de financiación del Banco Europeo, o bien al Mecanismo Europeo de Estabilidad. Incluso podrían haber apelado a la emisión de eurobonos (los famosos "coronabonos"), permitiendo así mutualizar la deuda y los riesgos bajo el paraguas de la UE. Esta propuesta, sin embargo, no fue respaldada por los países del norte. Lo mismo Estados Unidos, que también cuenta con vías de financiación, partiendo del privilegio exorbitante de financiarse en su propia moneda.

También la emergencia pone en aprietos a los detractores del Estado, sin otra alternativa que confiar en la salud pública. De hecho, una de las curiosidades ideológicas en la actual gobernanza del coronavirus han sido las recetas keynesianas. Los anuncios de paquetes económicos de ayuda y estímulo fiscal en casi todos los países parecieron rememorar las recetas de posguerra formuladas por John Maynard Keynes, más vigente que nunca.

Tal vez el caso más paradigmático sea el de Estados Unidos, que de la noche a la mañana aprobó a fines de marzo un paquete de estímulo fiscal que contempla la inyección de dos billones de dólares a través de transferencias directas a su población. De repente, las promesas "radicales" de Bernie Sanders parecen meras propinas. Si bien estas medidas se deben al contexto de emergencia, los ciudadanos podrán recordarlas cuando pronto les vuelvan a decir "no hay alternativa".

\section{Rivalidad hegemónica}

La desconfianza y la hostilidad entre Estados Unidos y China es otra de las tendencias preexistentes a la crisis que se ha profundizado desde la llegada del coronavirus al mundo. Ambas potencias libran una guerra de relatos para echarse la culpa sobre quién es el mayor responsable de la pandemia, alimentando todo tipo de teorías conspirativas.

La falta de reflejos a la hora de activar mecanismos de coordinación colectiva en pos de lograr respuestas efectivas ante el avance del virus evidenció la ausencia de un actor dispuesto a liderar la gobernanza global. En todo caso, queda claro que si alguien desea jugar ese papel hoy es China.

Los esfuerzos de su diplomacia por dejar atrás el estigma de haber sido donde se originó el virus (se habló de Wuhan como del "Chernóbil chino") y el haber ocultado inicialmente información delicada sobre el virus para mostrarse hoy como un país solidario con las recetas más efectivas para combatir la epidemia, abonan esa teoría.

El envío de insumos sanitarios a muchos países que pedían ayuda a gritos (como Italia y España) permiten pensar que ésta es la ocasión elegida por Beijing para avanzar casilleros en su aspiración de liderar el mundo, un papel que Trump nunca se mostró demasiado interesado en jugar. De esto se trata la transición del poder que ya estaba en curso: Estados Unidos declinaba y China emergía. El orden internacional se había transformado en una gran competencia comercial y tecnológica entre ambas potencias.

Al principio de la epidemia, el régimen comunista mostró serias dificultades en lidiar con el contagio. Su primera reacción, ocultando datos sobre el virus, reflejó el autoritarismo del régimen antes que la capacidad del Estado. Sin embargo, el cambio drástico de estrategia y la 
efectividad de su implementación les permite salir bien parados ante las demoras, titubeos y negaciones de Occidente.

Un dato de color: las cajas con insumos sanitarios que llegaban a diferentes rincones del mundo desde China contenían el mismo mensaje, una frase del filósofo Séneca que reza "Somos olas en el mismo mar, hojas del mismo árbol, flores del mismo jardín". A los ojos de quien recibe la ayuda, China aprendió de sus errores y no escatimó solidaridad. En palabras de Andrés Malamud (2020), "China llegó a la primera división del soft power, donde los países lideran por su capacidad de atracción y no de coacción” (p. 10).

La decisión de Washington de rechazar toda posibilidad de liderar un esfuerzo internacional que le haga frente al virus terminó por confirmar -si aún quedaban dudas- la absoluta falta de interés en ser el director de orquesta de una comunidad internacional de la que tampoco parece querer formar parte. Desde su llegada a la Casa Blanca, Donald Trump ha dado señales inequívocas de que el mundo no puede seguir contando con Estados Unidos para liderar el orden internacional, menos aún para la cooperación multilateral.

En otras circunstancias, una crisis de estas características habría empujado a Estados Unidos a asumir el liderazgo internacional movilizando recursos y reuniendo a los países para remar en la misma dirección. Eso fue lo que ocurrió tras el tsunami en el Sureste asiático de 2004, en la crisis financiera de 2008 y con el brote del ébola en 2014. De esta manera, la llegada del COVID-19 echó por tierra la teoría de America first, con la falsa premisa de que el bienestar y los intereses estadounidenses pueden quedar protegidos y defendidos de forma separada del bienestar del resto del mundo.

En un interesante artículo publicado en Foreign Affairs, Nicholas Burns, profesor en la Escuela de Gobierno de la Universidad de Harvard, alertó sobre la imperiosa necesidad de que Estados Unidos y China abandonen el juego de la culpa y comiencen a trabajar juntos en soluciones. Según el ex subsecretario de Asuntos Políticos en el Departamento de Estado, el punto más bajo de esta crisis política ha sido el fracaso de Washington y Beijing para dejar de lado sus tensiones más amplias y combinar fuerzas para combatir la pandemia. "Si China y Estados Unidos no pueden comunicarse y cooperar de manera efectiva, será casi imposible evitar nuevas tensiones, dividiendo un mundo que, ahora más que nunca, debería unirse y alcanzar una acción común”, advirtió (Burns, 2020).

Finalmente, concluía con un llamado de atención para su país: "La imagen de un Estados Unidos que no estuvo allí para ayudar al resto durante la crisis más grave en la vida de la mayoría de las personas, podría causar un daño irreparable a la forma en que el resto del mundo nos verá en el futuro".

Tras la llegada de la pandemia, los dirigentes políticos debieron enfrentarse al dilema de si enfermar a la población o a la economía. Algunos líderes populistas en Occidente -Donald Trump, Boris Johnson, Jair Bolsonaro y Andrés Manuel López Obrador, apodados "Los cuatro jinetes del coronavirus" por Malamud-, optaron inicialmente por enfermar a la población. Sin embargo, las presiones sociales y el efecto contagio los llevaron a revertir el curso, menos a uno: Jair Bolsonaro.

La reacción de estos líderes ha sido negar la realidad, y hoy estamos viendo las consecuencias. En el caso de Trump, de pasar a decir que el virus no era algo de lo que debíamos preocuparnos a liderar el medallero mundial de infectados demuestra la ineficiencia de estas políticas negacionistas. Estas mismas políticas llevaron además a que el mismo Boris Johnson se contagie de COVID-19. El pez por la boca muere.

\section{Hacia una vigilancia digital ampliada}


La pandemia ha demostrado el gran potencial que ofrece la tecnología digital en la emergencia global. Todavía no podemos saber cuándo se volverá a poner en marcha el mundo. Mientras tanto, de lo que podemos estar seguros es que se reforzará la tendencia hacia la digitalización en la salud, la educación y el mercado de trabajo.

En muchos sentidos, esta crisis equivale a una prueba de campo masiva. Millones de personas están experimentando nuevas formas de organizar su vida cotidiana. Los viajeros de negocios están reemplazando sus vuelos con videoconferencias. Los profesores universitarios dictan sus clases de manera virtual. Los empleados trabajan desde casa. Muchos volverán a sus viejos patrones después de la crisis. Muchos no.

Tras la aparición de la epidemia, muchos países -principalmente asiáticos- desplegaron un arsenal de dispositivos de control digital, ya sea para monitorear el cumplimiento de las reglas de distanciamiento social o para rastrear la propagación del virus. En este momento, 200 millones de cámaras de reconocimiento facial y miles de drones monitorean la circulación de personas por las calles chinas, donde cada instante de la vida cotidiana está sometido a observación. Los que aterrizan en Hong Kong reciben pulseras de rastreo electrónico que deben sincronizarse con la ubicación de su hogar a través de la señal GPS de su celular. Quien se aproxima en Corea del Sur a un edificio en el que estuvo un infectado recibe una señal de alarma.

"Se podría decir que en Asia las epidemias no las combaten sólo los virólogos y epidemiólogos, sino sobre todo también los informáticos y los especialistas en macrodatos", escribió Byung-Chul Han (2020). "Los apologetas de la vigilancia digital proclamarían que el big data salva vidas", expresó el filósofo surcoreano en una nota en el diario El País, donde expuso cómo los países asiáticos apelaron a la tecnología de control social para gestionar la epidemia.

En Occidente, mientras tanto, parece haber un gran consenso sobre la necesidad de una mayor vigilancia para proteger a sus propios ciudadanos. De hecho, la principal dificultad que enfrentaron las democracias a la hora de responder a la pandemia es la falta de datos sobre quién está enfermo o es contagioso y quién no. Sin esa información, los gobiernos se vieron forzados a decretar el cierre de sus fronteras y el confinamiento. En contraste con esas medidas extremas, las herramientas de control habilitadas por la inteligencia artificial se presentan como una solución aparentemente más afín al potencial tecnológico de estos tiempos.

No toda vigilancia es intrínsecamente maligna, y las nuevas herramientas tecnológicas podrían terminar desempeñando un papel destacado en la lucha contra el coronavirus, especialmente ahora que se empiezan a flexibilizar las cuarentenas. Así y todo, a nadie se le escapa que la adopción de estas herramientas no está exenta de riesgos. Muchos temen que estas medidas de emergencia terminen atentando contra nuestras libertades individuales y, sobre todo, que no se reviertan una vez que el virus haya quedado atrás. Una preocupación recurrente es que la adopción de estas medidas en plena pandemia -sorteando cualquier discusión o debate público- pueda ser algo así como un Caballo de Troya, perpetuando el estado de excepción actual.

Sobre esto advertía Yuval Noah Harari (2020) en un artículo publicado en marzo en el Financial Times: "Muchas medidas a corto plazo tomadas durante la emergencia se convertirán en parte integral de la vida. Esa es la naturaleza de las emergencias, aceleran los procesos históricos. Decisiones que en tiempos normales llevarían años de deliberación se aprueban en cuestión de horas", alertaba. El historiador israelí cree que nos enfrentamos al dilema entre vigilancia totalitaria y empoderamiento ciudadano.

¿Estamos cruzando un umbral en el uso de la tecnología? ¿Sacrificaremos libertad a cambio de seguridad, como hacen los países de Asia, que parecen estar combatiendo la 
epidemia con más eficacia (precisamente gracias a ese sacrificio)? ¿Permitiremos que nos controlen digitalmente con la promesa de protegernos mejor contra futuras epidemias?

Dos años atrás, Facebook protagonizaba la mayor filtración de datos de su historia, acusado de compartir sin permiso los perfiles de 87 millones de usuarios a la consultora Cambridge Analytica para influir en las elecciones que dieron a Donald Trump como ganador. Sin embargo, ante una pandemia como la que estamos viviendo, esos datos parecieran no tener el mismo valor. De dónde venimos, adónde vamos, con quién estamos, cuál es nuestra temperatura corporal. Todo pareciera estar justificado frente al miedo del contagio.

\section{Reflexiones finales}

Dependiendo de cuánto dure, el impacto del COVID-19 podría igualar al de una guerra mundial, en términos de la cantidad de personas que afecta, los cambios en la vida cotidiana que trae en cada continente y su costo humano. La ONU ya declaró que estamos ante la mayor crisis desde la Segunda Guerra Mundial. A su vez, el impacto en los negocios, el comercio y los mercados podría derivar en la crisis económica más devastadora desde la Gran Depresión.

Retomando las palabras de Dani Rodrik, el COVID-19 tal vez no altere -y mucho menos revierta- las tendencias evidentes antes de la crisis. "El neoliberalismo seguirá su muerte lenta. Los autócratas populistas se volverán aún más autoritarios. La hiperglobalización continuará a la defensiva mientras los Estados-nación reclaman espacio para implementar políticas. China y Estados Unidos se mantendrán en su curso de colisión. Y la batalla dentro de los Estados-nación entre oligarcas, populistas autoritarios e internacionalistas liberales se intensificará, mientras la izquierda lucha por diseñar un programa que apele a una mayoría de votantes".

Estamos frente a una encrucijada de la que podremos salir con una gobernanza global reforzada o con un mundo más cerrado. Si los países se vuelven unos contra otros, compitiendo por los escasos recursos disponibles, actuando en clave nacional antes que colectiva, no es impensable que puedan surgir nuevos conflictos y guerras. El camino que escojamos dependerá de nosotros.

TRABAJO RECIBIDO: 01/05/2020

\section{Referencias bibliográficas}

Burns, N. (2020). How to Lead in a Time of Pandemic. Foreign Affairs, 25 march

Guimón, P. (2020). El FMI prevé una caída de la economía global del 3\% en 2020, la mayor contracción desde 1930. Diario El País, 14 de abril. Recuperado de https://elpais.com/economia/2020-04-14/el-fmi-preve-una-contraccion-del-3-en-laeconomia-global-en-2020.html

Han, B.-C. (2020). La emergencia viral y el mundo de mañana. Byung-Chul Han, el filósofo surcoreano que piensa desde Berlín. Diario El País, 22 de marzo. Recuperado de https://elpais.com/ideas/2020-03-21/la-emergencia-viral-y-el-mundo-de-manana-byungchul-han-el-filosofo-surcoreano-que-piensa-desde-berlin.html 
Cuadernos de Política Exterior Argentina (Nueva Época), 131, junio 2020, pp. 107-114

ISSN 0326-7806 (edición impresa) - ISSN 1852-7213 (edición en línea)

Harari, Y. N. (2020). Yuval Noah Harari: the World afeter Coronavirus. Financial Times, March 20. Recuperado de https://www.ft.com/content/19d90308-6858-11ea-a3c91fe6fedcca75

Malamud, A. (2020). La globalización en peligro. Le Monde Diplomatique, 250, abril, pp.10-11

Rodrik, D. (2020). ¿El COVID-19 reconstruirá al mundo? Project Syndicate, 6 de abril. Recuperado de https://www.project-syndicate.org/commentary/will-covid19-remakethe-world-by-dani-rodrik-2020-04/spanish

Tokatlian, J. G. (2020). Pandemia: los conflictos del día después. Diario La Nación, 14 de abril. Recuperado de https://www.lanacion.com.ar/opinion/pandemia-conflictos-del-diadespues-nid2354082 